\title{
Estimating Parameters of Van Genuchten Model for Soil Water Retention Curve by Intelligent Algorithms
}

\author{
Xu Yang* and Xueyi You \\ School of Environmental Science and Engineering, Tianjin University, Tianjin 300072, China
}

Received: 30 Jan. 2013, Revised: 31 May. 2013, Accepted: 1 Jun. 2013

Published online: 1 Sep. 2013

\begin{abstract}
An improved particle swarm optimization (IPSO) was proposed and the intelligent algorithms such as IPSO, genetic algorithm (GA), and simulated annealing algorithm (SA) were introduced to determine parameters of Van Genuchten (VG) model for soil water retention curve (SWRC) of four typical agricultural soil textures (clay, clay loam, silt loam and sand loam) in China. For comparison, the SWRC in term of VG model was also fitted by a computer program RETC and pedotransfer function Rosetta, respectively. For four soil textures, the value of determination coefficient $\left(R^{2}\right)$ and root mean square error $(R M S E)$ in the estimation of VG equation parameters by IPSO are the highest and lowest in the above three intelligent algorithms, respectively. The simulated values of water content by IPSO are much closed to the measured values $\left(R^{2}=0.990\right)$. It was found that the Rosetta is unable to estimate the SWRC adequately and the highest $R M S E$ value is up to $1.096 E-01 \mathrm{~cm}^{3} \mathrm{~cm}^{-3}$. The predicted values of moisture content by Rosetta are far away from the measured values $\left(R^{2}=0.585\right)$. The RETC provided good simulation results of water content $\left(R^{2}=0.974\right)$. However, the soil residual water content $\left(\theta_{r}\right)$, of VG equation can not be obtained. It was concluded that the IPSO presented here is more reasonable and reliable to estimate the SWRC in term of VG model than the method of GA, SA, RETC and Rosetta.
\end{abstract}

Keywords: Soil water retention curve, Van Genuchten model, particle swarm optimization, genetic algorithm, simulated annealing algorithm, RETC, Rosetta.

\section{Introduction}

The soil water retention curve (SWRC), which is defined the relationship between soil water content and hydraulic potential, is an important physical property of soil material [1]. SWRC is indispensable when studying water flow processes and modelling water and solute movement through an unsaturated soil or when calculating the water availability for plants [2]. Empirical formulas are widely used to describe SWRC, where Van Genuchten (VG) equation is almost appropriate to all the soil textures [3]. However, four independent parameters need to be determined in VG equation, and the parameter fitting involves in the solution of nonlinear problems. Commonly-used least square method not only highly depends on the initial value of parameter, but also generates phenomena of algorithm termination and negative value.

Many researchers have been intended to solve these problems, which are mainly divided into the following 4 types.
(1) The optimization algorithms such as the nonlinear simplex method, Picard iterative approach, simplex evolutionary method and nonlinear damping least square were used to fit parameters of VG model $[4,5]$.

(2) The computer program, RETC [3], Data Processing System (DSP) and nonlinear function toolbox of MATLAB [6] were applied to estimate the VG equation parameters. However, the above approaches (1) and (2) strongly rely on the initial values of parameters. It is the same as the least square method.

(4) The VG equation parameters are indirectly estimated from basic soil properties such as sand, silt and caly fractions, bulk density, or water content at $-33 \mathrm{kPa}$ (corresponding to field capacity) and $-1500 \mathrm{kPa}$ (corresponding to permanent wilting point) using pedotransfer functions (PTFs) [9]. Bouma [10] introduced the term pedotransfer functions (PTFs), which was described as the predictive functions of certain soil properties from other easily, routinely, or cheaply measured properties. Rosetta is a pedotransfer function to estimate the parameters of VG model from surrogate soil

\footnotetext{
* Corresponding author e-mail: yangxu1009@ 163.com
} 
data such as soil texture data and bulk density [11]. Nevertheless, the errors between measured values of SWRC and predicted values determined from PTFs are larger than those of direct computation.

Therefore, a global optimization algorithm is urgently required to estimate parameters of VG model with a high accuracy. The new algorithm is hopefully independent on the initial values of parameters and the soil-column experiment is not required. Recently, the application of intelligent algorithm, such as generic algorithm (GA), particle swarm optimization (PSO) and simulated annealing algorithm (SA), has been introduced in hydrological sciences. However, no attempt on applying the intelligent algorithm to determine the SWCC was cited in the literature $[12,13]$. Thus, the objective of this study was:

(1) Improve the method of particle swarm optimization (IPSO) to avoid falling into local optimal solution and appearing the premature phenomenon;

(2) Compare the performance of three intelligent algorithms, i.e. IPSO, GA and SA, on estimating the VG equation parameters for SWRC;

(3) Compare the simulated results of IPSO with those of RETC and Rosetta.

\section{Van Genuchten Model}

The VG equation was proposed by van Genuchten in 1980 [14] with the expression as below:

$$
\theta=\theta_{r}+\frac{\theta_{s}-\theta_{r}}{\left[1+|\alpha h|^{n}\right]^{m}}
$$

where, $\theta$ is the soil water content $\left(\mathrm{cm}^{3} \cdot \mathrm{cm}^{-3}\right), \theta_{r}$ is the soil residual water content $\left(\mathrm{cm}^{3} \cdot \mathrm{cm}^{-3}\right), \theta_{s}$ is the soil saturated water content $\left(\mathrm{cm}^{3} \cdot \mathrm{cm}^{-3}\right), h$ is soil water potential $(\mathrm{kPa}), \alpha$ is a scale parameter inversely proportional to mean pore diameter $\left(\mathrm{cm}^{-1}\right), n$ and $m$ are the shape parameters of soil water characteristic, $m=1-1 / n, 0<m<1$. Under the conditions of available measured data of the soil water content and water potential, the parameters of VG model can be estimated by the least square method, i.e.,

$$
\min f=\sum_{i=1}^{N}\left(\theta_{i}-\theta\left(h_{i}, X\right)\right)^{2}
$$

where, $\theta_{i}$ is the $\mathrm{i}$-th measured soil water content $\left(\mathrm{cm}^{3} \cdot \mathrm{cm}^{-3}\right) ; h_{i}$ is the i-th measured soil water potential $(\mathrm{kPa})$ corresponding to $\theta_{i} ; \theta\left(h_{i}, X\right)$ is the soil water content $\left(\mathrm{cm}^{3} \cdot \mathrm{cm}^{-3}\right)$ calculated by Eq.(1); $X\left(\theta_{r}, \theta_{s}, a, n\right)$ is the parameter vector to be optimized; $\mathrm{N}$ is the number of measured data.

It is required to quantify the amount by which an estimated value differs from the measured value of the quantity being estimated. Such quantification describes how well the estimator describes the measured values. In this research, such differences between estimated values and the measured values are quantified using the following performance criterion:

(1) root mean square error (RMSE)

$$
R M S E=\sqrt{\frac{1}{n}\left(\sum_{i=1}^{N} P_{i}-M_{i}\right)^{2}}
$$

(2) determination coefficient $\left(R^{2}\right)$

$$
R^{2}=1-\frac{\sum_{i=1}^{N}\left(M_{i}-P_{i}\right)^{2}}{\sum_{i=1}^{N}\left(M_{i}-\bar{M}\right)^{2}}
$$

where, $P_{i}$ and $M_{i}$ are the predicted and measured values of the i-th measured data, respectively; $\bar{M}$ is the mean of measured values.

\section{Principle of numerical methods}

\subsection{Genetic algorithm}

GA is a randomly searching algorithm based on biospheric natural selection and population genetic mechanism. According to the gradient or higher-order statistics of a single metric function (evaluation function), a traditional optimization algorithm is used to generate a deterministic sequence of test solution. However, GA does not rely on the gradient information. It searches the optimal solution by stimulating the natural process of evolution. GA uses a coding technology with the effects on digital strings (chromosome) to simulate the evolution process of population. Through organized random exchange of information, the digital strings with better adaptability are reconstructed by GA to generate new populations. In order to eliminate the disadvantages of the standard genetic algorithm, i.e., premature convergence, a large computational complexity and poor solution accuracy, the real-coded genetic algorithm integrated with Levenberg-Marquardt method $[15,16]$ was used to determine parameters of VG model in this research.

\subsection{Simulated annealing algorithm}

SA was proposed by Metropolis in 1953, and successfully applied in combinatorial optimization by Kirkpatrick et al. in 1983 [17]. The thermodynamic process of physical annealing is stimulated in SA, and the solution and objective function are corresponding to particle state and its energy respectively. For a given initial temperature, the temperature descends according to the attenuation function, and the globally optimal solution of objective function is randomly searched by Metropolis rule in the solution space. The standard SA [17] was employed to estimate VG eqaution parameters in this study. 


\subsection{Improved particle swarm optimization}

PSO was jointly presented by a U.S. social psychologist James Kennedy and an electrical engineer Russell Eberhart in 1995 [18]. It was enlightened by the simulation results of birds behavior and the biological behavior model of Heppner and Grenander [19]. The basic PSO [17] is easy to fall into the local optimal solution and appear the premature phenomenon. To improve the basic PSO, an IPSO was proposed in this research. The new algorithm is a coupling of the constriction factor particle swarm optimization (CFPSO) of Clerk and Kennedy [20] and the PSO of Filedsend [21]. Although the convergence rate of CFPSO is fast, the diversity of species loses quickly and the premature convergence happens easily during the solution process. On the other hand, the species diversity of Filedsend PSO is good with computing procedure, but its global convergence rate is slow. Therefore, the improved PSO is proposed to inherit the advantages of the former two PSO models in order to overcome their shortcomings. Its basic principles of the IPSO are shown as follows.

It is assumed that a group is composed of $M$ particles in the D-dimensional search space with a certain flight speed. $x_{i}$ and $v_{i}$ are the position and velocity vector of $\mathrm{i}$-th particle respectively, i.e. $x_{i}=\left(x_{i 1}, x_{i 2}, \cdots, x_{i d}\right)$, $v_{i}=\left(v_{i 1}, v_{i 2}, \cdots, v_{i d}\right) . \quad p_{i}=\left(p_{i 1}, p_{i 2}, \cdots, p_{i d}\right)$ is the optimal position for a single particle and $p_{g}=\left(p_{g 1}, p_{g 2}, \cdots, p_{g d}\right)$ is the optimal position for all particles. In the iterative process, the velocity and position of particles are updated according to the following equation.

$$
\begin{gathered}
v_{i d}^{t+1}=K\left(v_{i d}^{t}+c_{1} r_{1}\left(p_{i d}^{t}-x_{i d}^{t}\right)\right. \\
\left.+c_{2} r_{2}\left(p_{g d}^{t}-x_{i d}^{t}\right)+\left(p_{g d}^{t}-p_{i d}^{t}\right)\right) \\
x_{i d}^{t+1}=x_{i d}^{t}+v_{i d}^{t+1}
\end{gathered}
$$

where, $i=1,2, \cdots, M$ and $d=1,2, \cdots, D . t$ is the iteration number, $r_{1}$ and $r_{2}$ are random numbers distributed uniformly in $[0,1], c_{1}$ and $c_{2}$ are learning factors, $\mathrm{K}$ is the contraction factor $\left(K=\frac{2}{\left|2-\varphi+\sqrt{\varphi^{2}-4 \varphi}\right|}, \varphi=c_{1}+c_{2}, \varphi>4\right)$, $v_{i d} \in\left[-v_{\text {max }}, v_{\text {max }}\right]$ and $v_{\text {max }}$ is the maximum speed.

\section{Materials and methods}

\subsection{Soil data}

The soil properties of four agricultural soil samples were adopted for the analysis, which were cited from China Soil Scientific Database. The basic physical properties of soil samples are shown in Table 1. The soil moisture content was determined by the disturbed core samples on silt bath at pressure of $0,1,3$ and $10 \mathrm{kPa}$, kaolinite bath at pressure of 20 and $33 \mathrm{kPa}$, and by the disturbed samples in high pressure pan at pressure of 250 and 1500kPa. Fig 1 displayed the SWRC of the four textures. It was found that the retention behavior of the textural classes is different from each other distinctly [22].

Table 1 Physical properties of four agricultural soil samples

\begin{tabular}{ccccc}
\hline \multirow{2}{*}{ Soil texture } & \multicolumn{3}{c}{ Particle composition \% } & \\
\cline { 2 - 4 } & $\begin{array}{c}\text { Sand } \\
2-0.05 \mathrm{~mm}\end{array}$ & $\begin{array}{c}\text { Silt } \\
0.05-0.002 \mathrm{~mm}\end{array}$ & $\begin{array}{c}\text { Clay } \\
<0.002 \mathrm{~mm}\end{array}$ & $\begin{array}{c}\text { Bulk density } \\
/ \mathrm{gcm}^{-3}\end{array}$ \\
\hline Clay & 15.0 & 76.0 & 9.0 & 0.99 \\
Clay loam & 42.0 & 29.0 & 29.0 & 1.49 \\
Silt loam & 11.0 & 12.0 & 77.0 & 1.10 \\
Sand loam & 57.0 & 12.0 & 31.0 & 1.27 \\
\hline
\end{tabular}

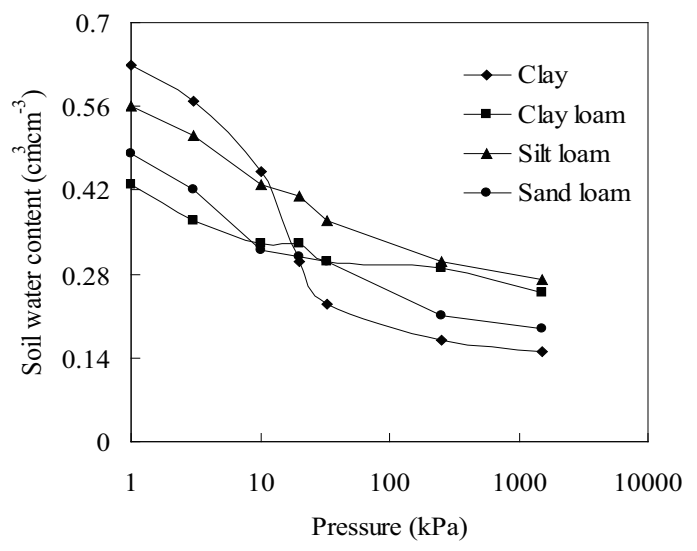

Fig. 1 Soil water retention curves for the four textures [21]

\subsection{Parameters determination of numeric methods}

The parameter setting of intelligent algorithm is a key factor that impacts the solution accuracy. According to the existing research results [23-26] and self-testing, the parameters of three intelligent algorithms were determined and was shown in Table 2. Rosetta offers five hierarchical sequences of input data: (1) soil textural class; (2) sand, silt and clay percentages; (3) sand, silt and clay percentages and bulk density; (4) sand, silt and clay percentages, bulk density and a water retention point at 33 $\mathrm{kPa}$; (5) sand, silt and clay percentages, bulk density and water retention points at 33 and $1500 \mathrm{kPa}$. It was demonstrated that the comparison of observed and estimated SWRC showed an increase in the regression 
Table 2 Parameter setting of the three intelligent algorithms

\begin{tabular}{|c|c|c|c|}
\hline Intelligent algorithms & IPSO & GA & SA \\
\hline \multirow{5}{*}{ Parameter setting } & Population size $=100$ & Population size $=100$ & Boltzmann Contant $=0.95$ \\
\hline & Neighboring population size $=2$ & Crossover rate $=0.85$ & Maximum inner loop $=100$ \\
\hline & Maximum speed=2 & Mutational rate $=0.01$ & Cooling coefficient $=0.9$ \\
\hline & Learning factor $c_{1}=2.05$ & Crossover=Uniform crossover & Initial temperature $=999$ \\
\hline & Learning factor $c_{2}=2.05$ & $\begin{array}{l}\text { Selection }=\text { Roulette } \\
\text { selection }\end{array}$ & $\begin{array}{l}\text { Energy transformation model=Single- } \\
\text { step transformation }\end{array}$ \\
\hline
\end{tabular}

coefficient $R^{2}$ value with an increase input predictors [27-30]. Therefore, the hierarchical level of item (5) of input data was used for this study.

\section{Results and discussion}

\subsection{Performance of intelligent algorithm for estimating parameters of $V G$ model}

Although the initial value of parameter of VG model is not required for the intelligent algorithms, it would be very helpful to shorten the workload and calculation time if the possible range value of each parameter is given. Therefore, the range of the parameters was given for intelligent algorithms and it was determined according to the literatures [31,32], where $\alpha$ was set as $0-1 \mathrm{~cm}^{-1}, \theta_{s}$ was set as: $0.5-0.6 \mathrm{~cm}^{3} \mathrm{~cm}^{-3}$ (clay), $0.4-0.5 \mathrm{~cm}^{3} \mathrm{~cm}^{-3}$ (loam), and $0.3-0.4 \mathrm{~cm}^{3} \mathrm{~cm}^{-3}$ (sand), $\theta_{r}$ was set as $0-0.2$ and $\mathrm{n}$ was between 1 and 10. Without loss generality, the possible value of $\mathrm{VG}$ equation parameters was chosen in the range of $\alpha \in[0,1], \theta_{s} \in[0.3,0.6]$, $\theta_{r} \in[0,0.2], n \in[1,10]$. The maximum iteration number of each algorithm was set to be 200. Each intelligent algorithm was run for 20 times and the solution of $\mathrm{VG}$ model corresponding to the lowest RMSE was listed in Table 3 .

The $R^{2}$ values in the estimation of $\mathrm{VG}$ equation parameters are equal or greater than 0.960 by the three intelligent algorithms, see Table 3 . The magnitude of $R M S E$ varies from 0.00618 to $0.03596 \mathrm{~cm}^{3} \mathrm{~cm}^{-3}$. Both the absolute errors of $\theta_{s}$ and $\theta_{r}$ of IPSO, GA and SA are equal or less than $0.006 \mathrm{~cm}^{3} \mathrm{~cm}^{-3}$. The value of $R M S E$ is the highest $\left(>0.03459 \mathrm{~cm}^{3} \mathrm{~cm}^{-3}\right)$ for clay and the lowest $\left(<0.00648 \mathrm{~cm}^{3} \mathrm{~cm}^{-3}\right)$ for silt loam. The $R^{2}$ and $R M S E$ values of $\mathrm{SA}$ are the lowest and the highest among the three intelligent algorithms. For clay and clay loam, the sequences of values of both $R^{2}$ and $R M S E$ from high to low and from low to high are all IPSO $>$ GA $>$ SA, respectively. The $R^{2}$ value in the estimation of $\mathrm{VG}$ equation parameters for silt loam by IPSO is equal to that by GA, and the RMSE value of IPSO is lower than that of GA. Both values of $R^{2}$ and $R M S E$ of IPSO are the same with those of GA for sand loam. The $R^{2}$ and $R M S E$ values in the determination of parameters of VG model for each soil texture by IPSO are the highest and lowest, respectively. All above results indicated that the parameter-optimization performance of IPSO is better than that of GA and SA.

\subsection{Comparison of IPSO with RETC and Rosetta}

The computer program RETC and PTF Rosetta are widely used to forecast SWRC in term of VG model. The nonlinear least square method is adopted in RETC and the initial values of $\mathrm{VG}$ equation parameters need to be set. Supposed that $\theta_{r}$ and $\theta_{s}$ are $0.1 \mathrm{~cm}^{3} \mathrm{~cm}^{-3}$ and $0.5 \mathrm{~cm}^{3} \mathrm{~cm}^{-3}$ respectively, $\alpha$ is $0.01 \mathrm{~cm}^{-1}$, and $\mathrm{n}$ is 1.1 in this study. The water content calculated by IPSO, RETC (version 6.02) and Rosetta (version 1.2) were compared with those of measurement, see Figs.2-4.

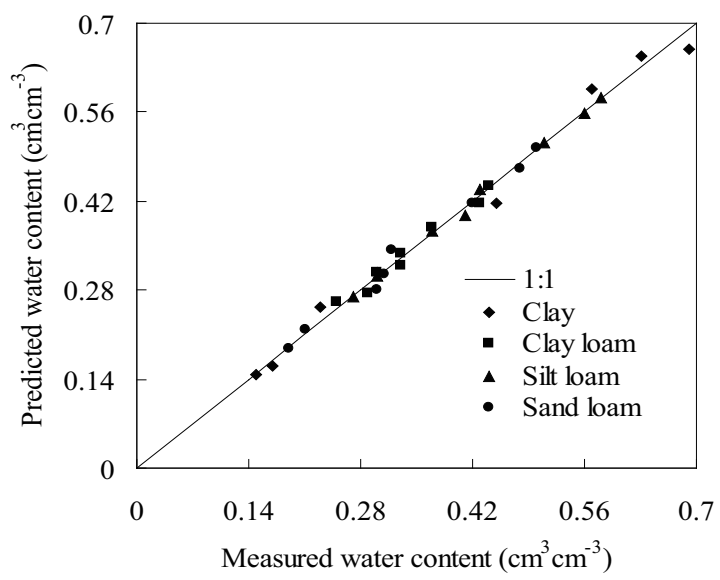

Fig. 2 Comparison of the predicted water content of IPSO with that of measurement [21] ( $\left.R^{2}=0.990\right)$.

Table 4 showed the $R^{2}$ and $R M S E$ values in determination of parameters of VG model by IPSO, RETC and Rosetta. It was found that the parameter of VG 
Table 3 Parameters of VG model obtained from three intelligent algorithms and statistical analysis for simulation results

\begin{tabular}{cccccccc}
\hline \multirow{2}{*}{ Soil texture } & Intellgient algorithms & \multicolumn{3}{c}{ Parameters of VG model } & \multicolumn{2}{c}{ Statistical analysis } \\
\cline { 3 - 7 } & & $\theta_{r} / \mathrm{cm}^{3} \mathrm{~cm}^{-3}$ & $\theta_{S} / \mathrm{cm}^{3} \mathrm{~cm}^{-3}$ & $\alpha / \mathrm{cm}^{-1}$ & $\mathrm{n}$ & $R^{2}$ & $R M S E / 10^{-2} \mathrm{~cm}^{3} \mathrm{~cm}^{-3}$ \\
\hline \multirow{3}{*}{ Clay } & IPSO & 0.154 & 0.600 & 0.103 & 2.365 & 0.981 & 3.459 \\
& GA & 0.160 & 0.600 & 0.096 & 2.649 & 0.979 & 3.487 \\
\multirow{5}{*}{ Clay loam } & SA & 0.158 & 0.600 & 0.095 & 2.825 & 0.977 & 3.596 \\
& IPSO & 0.197 & 0.444 & 0.986 & 1.225 & 0.965 & 1.220 \\
& GA & 0.193 & 0.440 & 1.000 & 1.207 & 0.962 & 1.223 \\
\multirow{3}{*}{ Silt loam } & SA & 0.191 & 0.438 & 0.947 & 1.201 & 0.960 & 1.257 \\
& IPSO & 0.200 & 0.585 & 0.535 & 1.272 & 0.997 & 0.618 \\
& GA & 0.200 & 0.581 & 0.484 & 1.276 & 0.997 & 0.627 \\
& SA & 0.195 & 0.581 & 0.532 & 1.259 & 0.996 & 0.648 \\
& IPSO & 0.155 & 0.505 & 0.571 & 1.344 & 0.989 & 1.138 \\
& GA & 0.155 & 0.505 & 0.569 & 1.346 & 0.989 & 1.138 \\
& SA & 0.159 & 0.511 & 0.627 & 1.401 & 0.988 & 1.185 \\
\hline
\end{tabular}

Table 4 Parameters of VG model obtained from three intelligent algorithms and statistical analysis for simulation results

\begin{tabular}{cccccccc}
\hline \multirow{2}{*}{ Soil texture } & \multirow{2}{*}{ Solution Methods } & \multicolumn{3}{c}{ Parameters of VG model } & \multicolumn{3}{c}{ Statistical analysis } \\
\cline { 3 - 7 } Clay & $\theta_{r} / \mathrm{cm}^{3} \mathrm{~cm}^{-3}$ & $\theta_{S} / \mathrm{cm}^{3} \mathrm{~cm}^{-3}$ & $\alpha / \mathrm{cm}^{-1}$ & $n$ & $R^{2}$ & $R M S E / 10^{-2} \mathrm{~cm}^{3} \mathrm{~cm}^{-3}$ \\
\hline \multirow{5}{*}{ Clay loam } & IPSO & 0.142 & 0.659 & 0.180 & 1.850 & 0.988 & 2.211 \\
& RETC & - & 0.693 & 0.529 & 1.301 & 0.966 & 3.684 \\
& Rosetta & 0.065 & 0.490 & 0.055 & 1.442 & 0.702 & 10.963 \\
& IPSO & 0.244 & 0.445 & 0.851 & 1.349 & 0.972 & 1.051 \\
\multirow{3}{*}{ Silt loam } & RETC & 0.244 & 0.445 & 0.849 & 1.349 & 0.972 & 1.051 \\
& Rostta & 0.136 & 0.413 & 0.053 & 1.321 & 0.588 & 4.020 \\
& IPSO & 0.227 & 0.582 & 0.445 & 1.327 & 0.997 & 0.540 \\
\multirow{3}{*}{ Sand loam } & RETC & - & 0.588 & 1.114 & 1.115 & 0.985 & 1.293 \\
& Rosetta & 0.131 & 0.580 & 0.045 & 1.230 & 0.340 & 8.728 \\
& IPSO & 0.155 & 0.505 & 0.569 & 1.346 & 0.989 & 1.138 \\
& RETC & - & 0.509 & 1.217 & 1.147 & 0.977 & 1.648 \\
\hline
\end{tabular}

Note: - indicates the parameter cannot be estimated.

equation of IPSO gives good results for the high $R^{2}$ value $(>0.97)$ and low $R M S E$ value $\left(<0.025 \mathrm{~cm}^{3} \mathrm{~cm}^{-3}\right)$. Fig. 3 showed that the predicted values by RETC are closed to the measured values ( $\left.R^{2}=0.974\right)$. It is also supported by the value of $R^{2}$ from 0.966 to 0.985 and $R M S E$ from 0.01051 to $0.03684 \mathrm{~cm}^{3} \mathrm{~cm}^{-3}$ in Table 4 . For clay loam, the value of $R^{2}$ and $R M S E$ of RETC is identical with that of IPSO. However, for clay, silt loam and sand loam, the parameter $\theta_{r}$ could not be obtained by RETC, and the sequences of both $R^{2}$ values from high to low and $R M S E$ from low to high are IPSO $>$ RETC $>$ Rosetta. It was found that the nonlinear least square method should be replaced by the method of IPSO to improve the accuracy of RETC in determination of the SWRC. For four soil textures, the value of $R^{2}$ and $R M S E$ of Rosetta is the lowest $(0.702,0.588,0.340$ and 0.529$)$ and highest $\left(0.10963,0.0402,0.08728\right.$ and $\left.0.09558 \mathrm{~cm}^{3} \mathrm{~cm}^{-3}\right)$, respectively. Fig. 4 showed that the results of Rosetta is not closed to the measured results $\left(R^{2}=0.585\right)$. It was indicated that the Rosetta was not suitable to determine the SWRC for the agricultural soil textures studied here. Fig. 2 showed that the predicted results of IPSO are very close to the measured results. It was demonstrated that IPSO is reasonable and reliable to estimate the SWRC of VG model. 


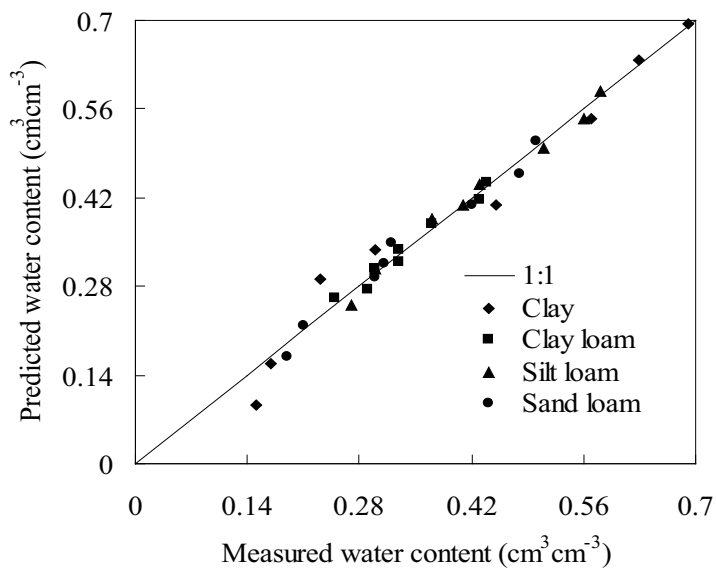

Fig. 3 Comparison of the predicted water content of RETC with that of measurement [21] $\left(R^{2}=0.974\right)$.

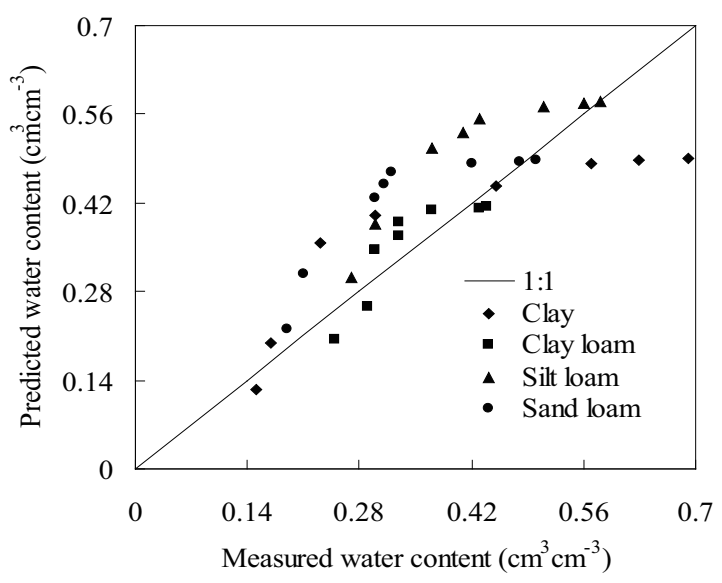

Fig. 4 Comparison of predicted water content of Rosetta with that of measurement [21] $\left(R^{2}=0.585\right)$.

\section{Conclusions}

An improved particle swarm optimization (IPSO) was presented in this study. The intelligent algorithms such as IPSO, GA, and SA were used to determine parameters of VG model for the SWRC of four agricultural soil samples in China. The coefficient of determination $\left(R^{2}\right)$ and root mean square error (RMSE) were used to quantify the differences between the predicted values and the measured values. The $R^{2}$ values for IPSO, GA and SA in the estimation of $\mathrm{VG}$ equation parameters are equal or greater than 0.960 . The $R^{2}$ and $R M S E$ values in the determination of parameters of VG model for four soil textures by IPSO are the highest and lowest, respectively.
It indicated that the performance of parameter-optimization of IPSO is better than GA and SA.

The fitted results of IPSO were compared with those of RETC and Rosetta. The predicted values of water content of RETC are closed to the measured values ( $\left.R^{2}=0.974\right)$. However, for clay, silt loam and sand loam, the parameter $\theta_{r}$ cannot be obtained by RETC at a given initial values of parameters. For the four soil textures, the value of $R^{2}$ and $R M S E$ of Rosetta is the lowest and highest, respectively. The results of Rosetta are far away from the measured results ( $R^{2}=0.585$ ). It was concluded that the method of Rosetta is not suitable to determine the SWRC of the four agricultural soil textures studied. The predicted results of IPSO are very closed to the measured results $\left(R^{2}=0.990\right)$. It was demonstrated that IPSO is more reasonable and reliable to estimate the SWRC in term of VG model than the method of GA, SA, RETC and Rosetta. The method of IPSO improves the accuracy of parameters determination of $\mathrm{VG}$ model and the elimination of initial value influence and the avoidance of soil-column experiment are also realized in present study.

\section{Acknowledgments}

This study was funded by the major of science and technology on national water pollution control and management (Grant No. 2009ZX07314-002-01). The soil data used in this research was cited from China Soil Scientific Database, http://www.soil.csdb.cn.

\section{References}

[1] B. Minasny, A.B. McBratney, K.L. Bristow, Geoderma, 93, 225-253 (1999).

[2] E. J. W. Koekkoek, H. Booltink, European Journal of Soil Science, 50, 489-495 (1999).

[3] M. T. Van Genuchten, F. J. Leij, S. R. Yates, The RETC code for quantifying the hydraulic functions of unsaturated soils, USEPA Report 600/2-91/065. U.S. Environmental Protection Agency, Ada, Oklahoma, (1991).

[4] X. Yang, X. Y. You, J. Min, L. M. Pan, X. D. Wang, L. J. Zhao, Proceedings of the International Symposium on Computer Science and Society (ISCCS), 97-99 (2011).

[5] X. Yang, X. Y. You, J. Min, Applied Mechanics and Materials, 160, 130-134 (2012).

[6] X. Z. Liu, X. X. Yu, S. J. Xu, African Journal of Agricultural Research, 20, 4800-4806 (2011).

[7] M. H. Young, A. Karagunduz, J. Simunek, Soil Science Society of America Journal, 66, 57-64 (2002).

[8] X. W. Han, M. A. Shao, R. Horton, Pedosphere, 20, 55-62 (2010).

[9] H. Merdun, O. Cinar, R. Meral, M. Apan, Soil \& Tillage Research, 90, 108-116 (2006).

[10] J. Bouma, Advances in Soil Science, 9, 177-213 (1989).

[11] M. G. Schaap, F. L. Leij, M. T. Van Genuchten, Journal of Hydrology, 251, 163-176 (2001). 
[12] A. Johari, G. Habibagahi, A. Ghahramani, Journal of Geotechnical and Geoenvironmental Engineering, 132, 661665 (2006).

[13] A. Johari, G. Habibagahi, A. Ghahramani, Scientia Iranica, 18, 1002-1008 (2011).

[14] M. T. Van Genuchten, Soil Science Society of America Journal, 44, 892-898 (1980).

[15] C. S. Park, IEEE Transactions on Magnetics, 35, 1582-1585 (1999).

[16] S. M. Abbas, I. Saleem, B. Ahmed, H. Khurshid, UWB Antenna with Parasitic Patch and Asymmetric Feed, Information Sciences Letters, 2, 27-33 (2013).

[17] S. Kirkpatrick, C. D. Gelatt, M. P. Vecchi, Science, 220, 671-680 (1983).

[18] J. Kennedy, R. C. Eberchart, Proceedings of the IEEE International Conference on Neural Networks, 1942-1948 (1995).

[19] M. N. Tabassum, R. Meer, Z. Ali, B-Positive Particle Swarm Optimization (B.P.S.O), International Journal of Computing and Network Technology, 1, 95-102 (2013).

[20] M. Clerc, J. Kennedy, IEEE Transactions on Evolutionary Computation, 6, 58-73 (2002).

[21] E. F. Jonathan, S. Sameer, A multi-objective algorithm based upon particle swarm optimisation, Proceedings of the UK Workshop on Computational Intelligence, 34-44 (2002).

[22] http://www.soil.csdb.cn/page/showEntity.vpage?uri=soilpro file201005.physical.

[23] M. R. Girgis, T. M. Mahmoud, H. F. Abd El-Hameed, Z. M. El-Saghier, Routing and Capacity Assignment Problem in Computer Networks Using Genetic Algorithm, Information Sciences Letters, 2, 13-25 (2013).

[24] F. Salvadori, C. S. Gehrke, M.de Campos, P. S. Sausen, A. C. Oliveira, A Hybrid Network Architecture Applied to Smart Grid, International Journal of Computing and Network Technology, 1, 45-59 (2013).

[25] R. Chechi, R. Khanna, Role of Swarm Technology based Routing in UMTS-WLAN networks, Applied Mathematics \& Information Sciences Letters, 1, 41-45 (2013).

[26] D. Weyland, Simulated annealing, its parameter settings and the longest common subsequence problem, Proceedings of the 10th Annual Conference on Genetic and Evolutionary Computation, 803-810 (2008).

[27] N. G. Patil, G. S. Rajput, Journal of Irrigation and Drainage Engineering, 135, 286-294 (2009).

[28] A. Nemes, M. G. Schaap, J.H.M. Wosten, Soil Science Society of America Journal, 67, 57-64 (2003).

[29] W. J. Rawls, Y. Pachepsky, M. H. Shen, Journal of Hydrology, 251, 177-185 (2001).

[30] J. H. M. Wosten, Y. A. Pachepsky, W. J. Rawls, Journal of Hydrology, 251, 123-150 (2001).

[31] J. J. B. Kool, J. C. Parker, M. T. Van Genuchten, Soil Science Society of America Journal, 49, 1348-1354 (1985).

[32] M. A. Shao, R. Horton, Soil Science Society of America Journal, 62, 585-592 (1998).

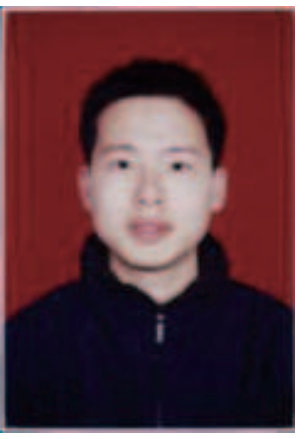

Xu Yang is Ph.D student in school of environmental science and engineering, Tianjin University. He received $\mathrm{ME}$ degree in the department of environmental and municipal engineering, Tianjin Institute of Urban Construction. The application of intelligent algorithms in soil information sciences is his research interests.

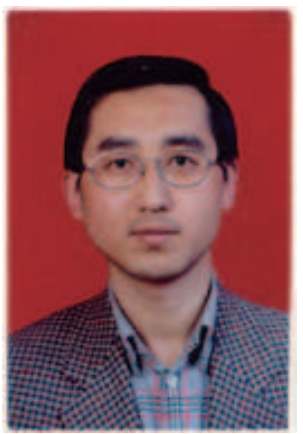

Xueyi You is a Professor in school of environmental science and engineering, Tianjin University. He received Ph.D degree in mechanics from Tianjin University in 1992. $\mathrm{He}$ has published more than 80 research articles in journals of mathematical and engineering sciences. His research interests are in the areas of microfluidics, mass and heat transfer and information systems. 